\title{
UNA TEORÍA PARA LA CUESTIÓN RACIAL DEL NEGRO EN BRASIL EL RECORRIDO DEL CÍRCULO VICIOSO
}

\author{
Helio Santos*
}

La invisibilidad de la temática racial en Brasil nunca fue tan grave como en la actualidad. A medida que el país busca consolidar la democracia, la lucha por la ciudadanía del negro, contradictoriamente, se diluye en las llamadas "cuestiones generales" del pueblo brasileño. Este empantanamiento se observa de manera más nítida desde la elección y toma de posesión del Congreso Constituyente (1986-87); y, después del Centenario de la Abolición (1988), entramos en un proceso de apatía profunda.

Es cierto, a pesar de todo, que lo que se acordó denominar como "Movimiento Negro" nunca pudo dar cuenta de la totalidad de la cuestión racial que, para nosotros, continúa siendo, en nuestro país, el nudo de la democracia en un sentido amplio.

Para comenzar es importante reconocer esa obviedad: el Movimiento Negro en Brasil es un pequeño extracto de la población negra y refleja como una muestra lo que viene a ser el pueblo negro en este país; trayendo consigo toda la carga de dificultades inherente a los descendientes de los esclavos de un país que fue el último en abolir la esclavitud y el primero del planeta en proclamarse una democracia racial. Después, sería necesario reconocer también que no hay, hablando con rigor, un sentido unitario en la lucha del negro en Brasil. Lo correcto, por lo tanto, sería hablar de Movimiento(s) Negro(s), en virtud de que existe un desfase razonable entre los diversos grupos en relación al nivel de comprensión del conjunto de la lucha. Finalmente, se debe reconocer también que el tamaño de las dificultades de orden político, material y teórico vuelven la cuestión tan compleja que ningún segmento aislado puede dar cuenta de la misma. De esta manera no es justo, en Brasil, exigir al Movimiento Negro la eficacia requerida para promover grandes avances en ese área sin el apoyo de la academia, de los partidos políticos, de las iglesias, del movimiento sindical y, sobre todo, del Estado y de los medios de comunicación de masas. De ser así, el Movimiento Negro se expandiría por la adhesión de aliados diferentes y que no tendrían porque ser necesariamente negros.

Todos los que se dedican al estudio de la cuestión de la cuestión racial en el país saben que tal problema es específico, dadas las idiosincrasias de la realidad brasileña. No es de esperar que el Movimiento Negro, solo, pueda gestar una teoría específica que facilite el avance real de esa lucha. La creación de una tec-

Traducción del portugués: Ana Inés López-Accotto.

(*) Profesor de la Facultad de Economía y Administración de la PUC-Campinas, ex-presidente del Consejo de la Comunidad Negra del Estado de Sao Paulo. nología específica que sirva de instrumental adecuado para tal batalla exige un tipo de conocimiento que aún está pendiente de desarrollo. De ahí el título de este artículo.

El presente trabajo es parte de un ensayo cuyo proyecto fue desarrollado con el apoyo del Centro de Estudos Afro-Brasileiros de Brasilia (CEAB) y del Conselho Nacional de Desenvolvimento Científico y Tecnológico (CNPq). En el estudio realizado buscábamos discutir la necesidad de disponer de una teoría específica para nuestra lucha específica.

Es sabido que la mayor fuerza del racismo y del prejuicio racial contra los negros en Brasil es consecuencia de la forma aparentemente blanda con que tales manifestaciones tienen lugar. Por otro lado, es sabido, también, que la gran debilidad del apartheid americano (hasta los años 60) y sur-africano (hasta recientemente) fue la forma absurdamente violenta con que se impedía el derecho de ciudadanía al pueblo negro. Ahora bien, frente a un racismo que se manifiesta de forma diametralmente opuesta, la idea de intentar actuar como los militantes negros americanos de los años 50 y 60 no fue una idea sabia. Tener como referencia al reverendo Luther King o al revolucionario Malcon X, o aún al entonces prisionero Nelson Mandela, fue el camino recorrido por el Movimiento Negro. En Brasil, el discurso racial no obtiene adhesión en virtud de la forma en la que el discriminado ve su realidad introspectivamente. ¿Por qué ocurre eso? Básicamente por la manera en que la discriminación racial se manifiesta entre nosotros, con sus mil caras, como en un caleidoscopio. Evidentemente, la cuestión se agrava fuertemente por la antigua fusión racial, innegable entre nosotros. Por lo tanto, el mestizaje es otro tópico con el cual los miembros del Movimiento negro sabemos lidiar muy bien. Lo que Gilberto Freyre denominó “fusionismo racial”, le llevó a creer que teníamos una democracia racial. Por otro lado, nuestro mejor aliado entre los científicos sociales, Florestan Fernandes, imaginó una cierta movilidad social de los llamados mulatos que más tarde se demostró que era falsa (Silva, 1980). Ambos, a pesar de mantener posiciones ideológicas opuestas, analizando el mismo hecho, fueron atraídos por lo que veían: una profusión de mestizos yendo y viniendo y creyeron que tal movilización física significaba movilidad social. Es lo que se puede llamar una ilusión óptica. Errores de ese tipo fueron los que más se cometieron, tanto por parte de la militancia negra, cuanto por parte de los estudiosos de la cuestión racial.

Entendemos que debe considerarse la dimensión cotidiana de las relaciones raciales para avanzar científicamente en ese 
tema. La vida se desarrolla en esa instancia - en el día a día- y no en otra.

Hace mucho tiempo que se viene "patinando" en esta cuestión sin que surjan nuevos aspectos relevantes, que faciliten la ampliación del conocimiento respecto de las relaciones entre negros y blancos en el país. El camino que se busca es necesariamente interdisciplinar. Los aspectos a ser tomados en consideración son múltiples. Son de naturaleza compleja y variada y, a nuestro entender, los diversos especialistas que investigan la temática racial no avanzaron tanto como habrían podido en virtud de haber estudiado aisladamente la cuestión en sus respectivos "nichos" de especialización. Antropólogos, historiadores y sociólogos -sobre todo estos últimos- se adentraron en la cuestión; algunos incluso como pioneros. No obstante, no descodificaron in totum ese ciempiés de dos cabezas que es la cuestión de la negritud en nuestro país.

Los sentidos del problema son dos: en una primera vertiente, tenemos la sociedad brasileña, que se supone blanca, discriminando al negro sofisticada y veladamente; en una segunda vertiente, tenemos al negro con la discriminación interorizada, dirigida hacia sí mismo. La mayoría de los autores simplifican la temática estudiando apenas la primera dirección de esa doble vía. No localizaron muy bien al propio negro avanzando a "contramano"*.

\section{PRESUPUESTOS DEL NUEVO ABORDAJE TEÓRICO}

La aproximación multidisciplinar en el estudio de la cuestión de la negritud en Brasil fue la conclusión del Seminario "Por una teoría de la cuestión negra", realizado el 29 de octubre de 1987, por la Coordinadora de Actividades Culturales de la USP. Básicamente, el Seminario reconocía que: "El tratamiento interdisciplinar de la cuestión negra en nuestro país permitirá el estudio amplio e interrelacionado de todos los aspectos de esa problemática, a diferencia de las aproximaciones sectoriales efectuadas hasta ahora". Los diversos tópicos que constituyen las dificultades sufridas por los no-blancos en Brasil tienen una secuencia que se comprende mejor mediante un enfoque sistémico, en el que un determinado problema es visualizado como un todo, con sus múltiples relaciones y conexiones. Como se sabe, "la metodología sistémica tiene como esencia el conocimiento de las múltiples interrelaciones de los diversos componentes de un problema. A partir de esta visión de conjunto, esta metodología posibilita conocer de manera integrada los diversos sectores existentes". (Santos, 1988:48). Lo que se busca, básicamente, es impedir la superespecialización que acaba dando mayor énfasis a las partes aisladas de la problemática racial, en vez de abarcarla globalmente. La propuesta se ocupa de revertir esa idea de "compartimentalización" del estudio de la cuestión negra en Brasil.

Resumiendo, los presupuestos de la nueva aproximación trazados por este estudio son tres. En primer lugar, tenemos la multidisciplinariedad conjugada con la idea de interdisciplinariedad. Las áreas que se deben trabajar en la cuestión racial brasileña son múltiples. Por otro lado, existe una amplia conexión entre

* Expresión que equivale a “dirección prohibida” en el lenguaje vial (N. de T.) esas disciplinas que no deben ser estudiadas sin tomar en cuenta las diversas interrelaciones que existen entre ellas. En segundo lugar, se tiene como foco básico del estudio la cotidianeidad, en la que tienen lugar los hechos. Es en lo cotidiano donde deben buscarse y seleccionarse los tópicos a estudiar. En tercer lugar, aparece la idea de circularidad que caracteriza a nuestro estudio. Tal idea viene a remolque del enfoque sistémico que interrelaciona todos los tópicos "pescados" en lo cotidiano.

Por lo tanto, la interdisciplinariedad, lo cotidiano social y la circularidad aportada por el enfoque sistémico, constituyen la base en la que se asienta la Teoría del círculo vicioso.

Damos al conjunto de dificultades específicas enfrentadas por el pueblo no-blanco (negros y pardos) de Brasil el nombre de "recorrido del círculo vicioso" porque, como se verá, esa es la característica que promueve el desarrollo diferenciado entre blancos y no -blancos en el país.

\section{EL RECORRIDO DEL CÍRCULO VICIOSO}

La situación socio-económico de la población no-blanca se explica históricamente por la manera que se dio la abolición. En lo que se refiere a la problemática negra en Brasil, no hay manera de obviar la esclavitud. Sin un enfoque histórico, no podemos entender la subciudadanía impuesta a los no-blancos, que tiene como origen la forma como se produjo la abolición entre nosotros.

\section{LA FORMA COMO SE DIO LA ABOLICIÓN}

Brasil sería otro país hoy en el caso de que la abolición hubiese estado acompañada por una adecuada reforma agraria, en la que las familias de los ex-esclavos hubieran recibido pequeñas propiedades agrícolas aptas para la producción. Tales familias, como es sabido, tenían entonces una secular experiencia rural.

Ruy Barbosa sintetiza bien cuando afirma que el abolicionismo se configuraba en el "entusiasmo nacional" en conflicto con el latifundio, los conservadores y la monarquía. En el contexto sintetizado por Ruy, sin embargo, puede sonar extraño, a primera vista, que la abolición viniera de las manos de un gabinete conservador (João Alfredo). La explicación está muy bien presentada por Ferreira Viana, ministro de Justicia del gabinete de João Alfredo, que entendía que no cabía, de hecho, la extinción de la esclavitud. Para el ministro de Justicia del gobierno que "liberó" a los esclavos, lo que cabía hacer era declarar la esclavitud "extinguida" (sic). Es lo que finalmente se hizo. El artículo $1^{\circ}$ de la Ley 3.353, del 13 de mayo de 1888, dice: "Se declara extinguida la esclavitud en Brasil".

Excepto en los casos en que los ex-esclavos continuaron trabajando en las haciendas, la masa negra partió hacia la periferia de las ciudades de donde nunca más salió. El proceso de chabolismo urbano, a partir de entonces, se acrecentó. Las enfermedades (sífilis, tuberculosis, lepra, esquitosimosis y otros males, como la locura) redujeron la vida media de la población negra. El deterioro del pueblo negro se aceleró desde entonces. De un lado, la desvalorización profesional, representada por el abaratamiento salarial; de otro, un aspecto más grave, porque es de orden psicológico, el estigma secular de haber sido esclavo 
durante tanto tiempo. Es importante recalcar que Brasil fue el último país en abolir la esclavitud.

\section{LA DICOTOMÍA: BAJA RENTA Y ESCOLARIDAD INFERIOR}

Discriminado en el mercado de trabajo -tanto en las funciones más simples como en las más complejas- (Oliveira, 1981:29) el no-blanco no puede invertir (y tampoco se siente estimulado) como los demás (blancos, judíos y amarillos) en su capacitación profesional. Por otro lado, se encuentra profundamente huérfano en términos de capital social. Finalmente, su pedigree es el senzala ${ }^{1} .$. Tal marca atávica no puede refrendar positivamente a un ciudadano pleno en virtud de los preconceptos de origen. No se debe olvidar que muchos autores entienden que el racismo contra el negro es resultado de la extensión de la esclavitud (Golden, 1964). Ahora bien, en un país donde las cartas de presentación constituyen la base de prácticamente todas las relaciones (económicas, políticas y personales), quien tiene como referencia al senzala no va a competir ni a participar en igualdad de condiciones con los demás.

Una buena política de personal es la que busca obtener en el mercado el mejor material humano disponible a fin de lograr los múltiples objetivos de la organización. Ahora bien, el negro en la sociedad brasileña está lejos de ser visto como el prototipo del más capacitado. Por lo tanto, según las técnicas usuales para la selección de personal, el no-blanco no es visto como el más adecuado para desempeñar funciones importantes, y ni siquiera algunas actividades menos relevantes dentro de las empresas, tales como botones, recepcionistas, simples dependientes de mostrador, etc.

En el mercado de trabajo los impedimentos a los negros tienen lugar durante todo el proceso: muchas veces ya en el reclutamiento, mediante el sutil concepto (o preconcepto) de "buena apariencia”; en la selección, mediante evaluaciones subjetivas o inadecuadas para definir la real capacitación del candidato; en las promociones, muchas veces, tiene lugar una "parada", en la que una persona no-negra, menos cualificada o con menos tiempo de servicio que un concurrente negro es promovida en detrimento de éste y, finalmente, a la hora de los despidos, en los que generalmente los negros acaban siendo los primeros en salir esto tanto en los momentos de crisis recesivas como en los despidos rutinarios. Esto es, la tasa de turnover* de los negros y pardos es mayor de la de los no-negros.

Además de eso, quedan dos aspectos: la cuestión de la cualificación, en la que el negro está originariamente perjudicado en virtud de no disponer de recursos que le permitan invertir en educación, y la inexistencia, casi absoluta, de capital social.

En relación a la alegada falta de preparación del negro, es cierto que las mejores escuelas (generalmente las universidades públicas y gratuitas) no están abiertas a los más pobres. A ellas llegan los pudientes y los diversos sectores de la clase media. Raramente los más pobres (negros y pardos en su mayoría) tienen acceso a un tipo de enseñanza que requiere una precapacitación inalcanzable para quien desde la gestación ya estaba en posición desventajosa. Los llamados 'vestíbulos de acceso' a

\footnotetext{
(1) El patio donde vivían los esclavos en las plantaciones (N.T)
}

* En inglés en el original, se refiere a la tasa de reemplazo (N. de T.) las universidades públicas son semejantes a una corrida entre una liebre y una tortuga (el resultado de esa disputa o es como en la fábula, en la que el quelonio vence. En la vida real la liebre sale primero y gana compitiendo sólo con otras liebres).

Además de eso, la escuela, sobre todo la pública, no facilita el desarrollo del alumno negro. Conforme demuestra el estudio hecho por Rosemberg (1987), las tablas de la Pesquisa Nacional por Amostra de Domicilios (PNAD), de 1982, evidencian un mayor índice de repetidores entre los niños negros (negros y pardos) en todas las series de I grado. Para la $1^{\underline{a}}$ serie de I grado, el índice de fracaso escolar de los niños negros es del $41 \%$ frente al $29 \%$ de los niños blancos. En cuanto al paso de $3^{\mathrm{a}}$ a $4^{\mathrm{a}}$ serie, el $10 \%$ de los niños negros dejan la escuela, mientras que la tasa de abandono de los niños blancos es de apenas el 5\%. Por otro lado, la vida escolar de los negros es bastante más accidentada que la de los blancos. Los niños negros sufren un número de salidas y retornos superior al de los niños blancos.

Las escuelas que atienden a los necesitados también son pobres. En opinión de Rosemberg, un sistema de cuotas destinadas a la población no-blanca se enfrentaría dificultades de todo orden: operacional, político, etc. Lo más adecuado sería invertir en educación (más y mejores escuelas) en las regiones donde la población negra representase una franja significativa de la clientela escolar. La segregación espacial de los segmentos raciales permite hacer un mapa de las regiones con un perfil adecuado para recibir mayor atención del sector público.

Tenemos, pues, en el origen del recorrido del círculo vicioso las dificultades económicas y educativas de los no-blancos. Las primeras reforzando a las últimas y éstas impidiendo la modificación de aquéllas...La dicotomía "baja renta/escolarización inferior" ocasiona las razones estructurales de las diferencias entre negros y blancos en el país. Al mismo tiempo, sus efectos, como se verá a continuación, tienen un fuerte componente psicosocial que acaba definiendo y reforzando el tipo de confusión que enfrentamos ante la temática de la cuestión negra. Tales efectos se van a reflejar en el plano del pensamiento colectivo, en el que el prejuicio y la no-identidad tienen un papel significativo.

\section{LA VISIÓN DE LA SOCIEDAD}

Las dificultades económicas y educacionales sumadas son, en gran parte, la causa de la visión errónea y discriminatoria que la sociedad acaba teniendo en relación con los negros y pardos. El sector atrasado del país no es blanco: innumerables análisis socio-económicos con los cortes raciales evidencian este hecho. Todo ello agravado por el hecho de que el Brasil desarrollado cree que la inmovilidad social de los no-blancos es producto de una incapacidad natural de éstos. Esta es, en general, la concepción de la sociedad, aunque sin explicitar objetivamente esa visión discriminatoria.

Para Munanga (1990), las teorías que intentan explicar la complejidad del racismo son numerosas y muchas veces contradictorias. Esta autora cita dos aspectos básicos a destacar en el estudio del problema: por un lado, la división o clasificación del género humano hecha por los científicos sociales, en "variedades generalmente denominadas razas", como los demás científicos hacen en zoología al clasificar los animales y en botánica, al seleccionar las plantas; y por otro, el hecho de que en la socie- 
dad moderna occidental, a partir de esa clasificación, se sacan conclusiones absurdas e injustas "...en nombre de las cuales el hombre blanco se daba el derecho de explorar, dominar, humillar y hasta de exterminar a otros hombres."

Por otro lado, los científicos que trabajaban con esa clasificación -los antropólogos- serían inocentes en el caso de que hubiesen actuado a semejanza de los zoólogos y los botánicos, que no buscaron jerarquizar las especies seleccionadas en sus estudios. Los antropólogos, en vez de clasificar a los diversos grupos humanos en función de sus características físicas solamente, pasaron a jerarquizar a tales grupos, mediante criterios sin una base que pudiéramos llamar científica. A ese respecto, Munanga dice que: "En el nivel actual de nuestros conocimientos, no existe relación entre caracteres físicos o biológicos y las disposiciones intelectuales o morales de un individuo" (Penteado, 1993).

Retomando el análisis de la "visión de la sociedad" es necesario aclarar que tanto los medios de comunicación como la policía, así como la propia población negra forman parte de la sociedad. En nuestro estudio, destacamos los diversos sectores que deben ser estudiados aisladamente para la comprensión del todo, con el fin de enfocar la implicación sistémica de todo el proceso.

\section{LOS MEDIOS DE COMUNICACIÓN}

Los medios de comunicación (radio, revistas, diarios, literatura y, sobre todo, televisión) poseen la visión de la sociedad dominante y existen para ésta.

El Conselho da Comunidade Negra, en San Pablo (198487), se esforzó para que las agencias de propaganda transmitiesen el concepto de negro de una forma positiva, a fin de ayudar a revertir los estigmas acumulados a lo largo de la opresión secular de que fue víctima. A partir de esta época, se comenzó a dar al negro un espacio no sólo mayor, sino también un espacio donde no era ridiculizado como antes. Esto no significa que los no-blancos dejaron de ser invisibles. La invisibilidad continúa siendo la marca del negro en los medios de comunicación, sobre todo en la televisión.

En cuanto a la propaganda, es bastante pertinente la pregunta hecha por el publicitario José Roberto Whitacker Penteado (Cury, 1985): “¿Cuál es el corazón de nuestro mercado?”. Existe un acuerdo por parte de muchos publicitarios en cuanto a que los negros aparecen menos en la propaganda porque consumen menos. Así mismo, en el artículo Penteado asevera haber encontrado "...fuerte indicios de que cerca del $20 \%$ al $25 \%$ de todo el consumo de bienes y servicios de marca en Brasil...podría ser atribuido a 'mestizos' y 'negros"'. Es importante aclarar que no se trata de bienes y servicios de consumo popular, sino de imagen de marca.

Penteado concluye en su artículo que "nuestro mercado de productos femeninos es absolutamente europeo". Llega a esa conclusión después de constatar, mediante un estudio estadístico, que no existen anuncios con modelos negros en revistas femeninas dirigidas a los estratos superiores del mercado. Lo más grave del caso de las modelos es que en el exterior, especialmente en la blanca Europa, las modelos negras son ampliamente valoradas.

En un seminario promovido por el Conselho de Participaçao e Desenvolvimento de la Comunidade Negra, en 1986, sobre la discriminación racial en los medios de comunicación, las conclusiones revelan que en todas las áreas de la comunicación social (literatura, prensa escrita, hablada y televisada, propaganda, teatro, cine) tiene lugar la divulgación negativa del elemento negro, el cual aparece, generalmente, como un individuo no-pensante. Es decir, en el que el cuerpo cuenta más que el intelecto.

\section{LA VIOLENCIA POLICIAL}

En el recorrido del círculo vicioso también tenemos la represión policial (sobre todo la policial-militar) contra los noblancos. En cuanto a ese particular, nada más natural: el Brasil desarrollado, el mundo blanco que es el país oficial, tiene en las policías (civil y militar) su brazo armado. En la medida en que la sociedad tiene a los no-blancos como marginados en potencia es razonable que las policías (sobre todo la militar) dedique a éstos su mayor atención. El problema, no obstante, está en el hecho crucial de que es bien diferente enfrentar a un racista en una selección para un empleo que enfrentarse a un racista armado; y aún peor: a sueldo del Estado. La violencia policial contra los negros es un fenómeno mundial. Mientras tanto, aquí en Brasil, la impunidad es lo que escandaliza a todos.

El pueblo humilde y pobre, en su vasta mayoría 'negro y pardo', vive "emparedado", entre dos frentes. De un lado están los marginados que asolan no sólo los centros de las ciudades, sino también la periferia, favelas y morros. Y, de otro, tenemos a la propia policía que, como los marginados, anda suelta y armada por las calles.

En el caso de las policías, no sólo los no-blancos más humildes corren riesgo. Aquello que podríamos llamar 'clase media negra' no está libre de la violencia policial, como podrían imaginar algunos incautos. Entre los agredidos por las policías tenemos desde artistas detenidos absurdamente, evidenciando de forma descarada la miopía racista con la que actúa la policía, hasta autoridades extranjeras (negros, evidentemente) que visitan el país.

Dos casos absurdos: el conocido cantante y compositor Djava es detenido por Policías Militares en el centro de Sao Paulo, “...por exceso de documentos”. Por lo menos esa es la posible razón identificada por el artista al ser abordado por los policías. Djavan llevaba consigo todos los documentos posibles, incluyendo el pasaporte y la carta de músico. Fue llevado a la delegación y liberado rápidamente por un aturdido delegado que, lo reconoció, le pidió disculpas; el otro caso se refiere a una increíble agresión, violenta e inusitada, sufrida -sorpréndanse todos- por el ex-presidente de Surinam, Desi Bourtese. Más grave aún: el ex-presidente estaba acompañado por diplomáticos, incluyendo una mujer que también fue empujada y pateada por los policías. Toda la comitiva de negros encorbatados fue identificada como asaltantes de bancos por los Pms (policías militares). Tal embrollo costó al Ministerio de Relaciones Exteriores y al Ministerio de Justicia, avergonzados, explicaciones a los invitados que visitaban el país por negocios.

En Brasil son raros los negros urbanos que no han experimentado todavía graves sinsabores y agresiones de las policías (Civil y, sobre todo, Militar).

\section{LA NO-IDENTIDAD RACIAL DE LOS NO-BLANCOS}

Durante casi tres siglos y medio, el negro fue esclavizado: de 1543 a 1888. Ese período tan largo estigmatizó al negro como infrahumano. La verdad es que el negro fue categorizado como 
alguien incapacitado para la plena ciudadanía. Por otro lado, el negro fue empujado a creer, efectivamente, en eso. Tenemos a partir de ahí la 'contramano' citada en nuestro estudio: la identidad (más acertado sería decir la no-identidad) del no-blạnco brasileño.

Las prácticas escolares definen la "concepción del mundo" de los niños. Es lo que Cury (1985) llama el "ritual pedagógico". Tal ritual, en la opinión de Gonçalves (1987), excluye la lucha de las poblaciones negras en la sociedad brasileña. Más aún: el ideal de 'ego blanco' es lo que los críos negros pasan a reivindicar para sí en ausencia de una identidad que los pueda fortalecer.

Kabengele Munanga, en su ensayo sobre identidad y negritud, afirma que es común indagar si es posible en Brasil "la existencia de una identidad de negros diferente de los demás ciudadanos”. Dice más: “...otros llegan a indagar si las denominadas 'negritud e identidad negras' no pueden ser vistas como una división de lucha de todos los oprimidos". (Munanga, 1991:1) El discurso militante habla de identidad "afro-brasileña" y de negritud como forma de buscar una identidad perdida. Lo que Munanga cuestiona (Munanga, 1991:7), con lo que estamos de acuerdo "in totum", es si tales conceptos encuentran resonancia en el pueblo negro. Como se sabe, la alienación del negro brasileño pasa por la desvalorización de su cultura y de su físico. La cultura negra ya está expropiada y, en rigor, forma parte de la cultura nacional. Esto es, pertenece a todos los brasileños (negros y no negros). Y además, ser negro no es algo apetecible en un país emblanquecido ideológicamente. Para la juventud negra tales aspectos son aún más sensibles que para los más viejos. En Brasil, el Movimiento Negro sigue actuando mucho en la línea de defensa de la cultura negra. En su ensayo, el profesor Munanga afirma que tal postura "no crea ningún problema cuando no está acompañada de la reivindicación política". Y aún peor: "la retórica oficial se expresa a través de las propias contribuciones culturales negras en Brasil, para negar la existencia del racismo y para afirmar la proclamada “Democracia Racial” (Munanga, 1991:9).

\section{EL MANTENIMIENTO DEL STATUS QUO}

Cerrando el recorrido del círculo vicioso tenemos el mantenimiento de la situación en que se perpetúa a los negros en Brasil. Como los mismos no-blancos (negros y pardos) interiorizan las ideas racistas y prejuiciosas construidas contra sí mismos, la identidad racial negro-afro-brasileña no se afirma, incapacitando así la alteración de este cuadro por la vía del discurso racial. La rueda de las dificultades gira indefinidamente permitiendo cambios pequeños para parcelas restringidas de la población negra, sin conseguir con ello alterar significativamente el conjunto. Cambios éstos también más lentos que para el resto de la población. Este giro tiene, efectivamente, una característica inmovilizadora perversa, porque simula con extrema eficacia que las dificultades sufridas por los negros son de su exclusiva responsabilidad. No sólo la población blanca cree eso. Es importante saber que es inmenso el número de negros que piensan así.

La perpetuación de la subciudadanía de los descendientes de los esclavos es un fenómeno marca que mantiene al país en el Tercer Mundo. Es impensable la idea de modernidad en un país partido por la mitad. Hay, en realidad, dos Brasiles: el primero es bien parecido a algunos países europeos -una Bélgica, a título de ejemplo. Ese primer mundo tiene como vecindad el peor de los mundos: el Brasil no-blanco. Ese segundo Brasil es el máximo campeón en endemias que se supone ya extintas y es también donde tiene lugar un fuerte déficit habitacional.

El país está inconcluso porque no sabe transformar a los antiguos esclavos y a sus descendientes en ciudadanos plenos. El combate contra la pobreza en Brasil fue olvidado por las élites, precisamente por el hecho de que la miseria alcanza y toca mayoritariamente a la población no-blanca, razón por la cual las clases dirigentes nunca se preocuparon. Este hecho no se da en países como Japón o Alemania. Pueblo y élite, en aquellas naciones, tienen una misma raíz racial, lo que mantiene una fuerte ligazón entre las clases dirigentes y el resto de la población. En estos casos, las políticas públicas buscaron fortalecer al pueblo y la vertiente educativa fue el ítem en el que más se invirtió.

Siendo así, no tiene sentido el uso difundido por los intelectuales brasileños de un concepto nuevo entre nosotros: el de apartheid social. Mientras en Sudáfrica el apartheid legal llega a su fin, aquí no tenemos ojos para ver que la aplastante mayoría de las personas que viven por debajo de la línea de pobreza no son blancas. Lo más grave, sin embargo, es saber que el apartheid brasileño se perpetúa, precisamente por ser, en realidad, "cuasi racial” en sí mismo. Como ya observamos, las élites dirigentes se han mostrado insensible al barbarismo social, en virtud de la (supuesta) desconexión racial entre ellas y las masas -en su mayoría negra y mestiza. Como el carácter racial de la división de la renta eterniza a los negros en el papel de pobres e incultos y como las élites constituyen más de la mitad de la población, podemos afirmar que el Brasil rico y próspero es blanco. Consecuentemente, el segundo Brasil -miserable y atrasado- está compuesto, en su mayoría, por no-blancos.

La experiencia con la que las élites brasileñas se obstinan en continuar da señales de agotamiento. Básicamente ellas operan así: hablan de modernidad y se posicionan en escenarios del siglo XX. Al mismo tiempo, cuando actúan están fijadas obstinadamente en el siglo XVIII. La modernidad exige la transformación de la sociedad en otra que tenga como base el uso intensivo de ideas racionales, es decir, eficaces. El apartheid cuasi-racial brasileño no es algo que se pueda entender como racional. El mantenimiento de la situación racial-económica-social del negro es la causa de la inconcreción del país ambiguo y excluyente que tenemos: rico y miserable; próspero y, al mismo tiempo, anacrónico. En suma, blanco y negro.

\section{UNA TEORÍA ESPECÍFICA PARA LA NEGRITUD BRASILENA}

La búsqueda de una teoría específica para la cuestión negra en Brasil brasileña parece ser el camino adecuado, hoy, para iniciar cambios que posibiliten el desarrollo armonioso del país. En el punto inicial fijamos los presupuestos de una probable teoría de la cuestión negra brasileña y en los dos puntos siguientes presentamos, de una forma general, la idea sobre la cuestión.

\section{EL ESQUEMA GRÁFICO DEL RECORRIDO DEL CÍRCULO VICIOSO}

El esquema gráfico da una visión completa de lo que denominamos "el recorrido del círculo vicioso". Nuestro presupuesto es 
que los obstáculos al desarrollo de los no-blancos en Brasil constituyen un sistema circular en que las partes (subsistemas) que componen el todo, impulsan, a veces en forma difusa, las dificultades. En otras palabras: un determinado subsistema es originado por uno que le antecede. Tal subsistema, a su vez, es la causa de aquel que le sucede. O sea: los efectos de un subsistema antecedente constituyen la causa del subsistema subsecuente y así sucesivamente, hasta retornar al punto inicial (ver esquema gráfico).

Figura I

El recorrido del círculo vicioso

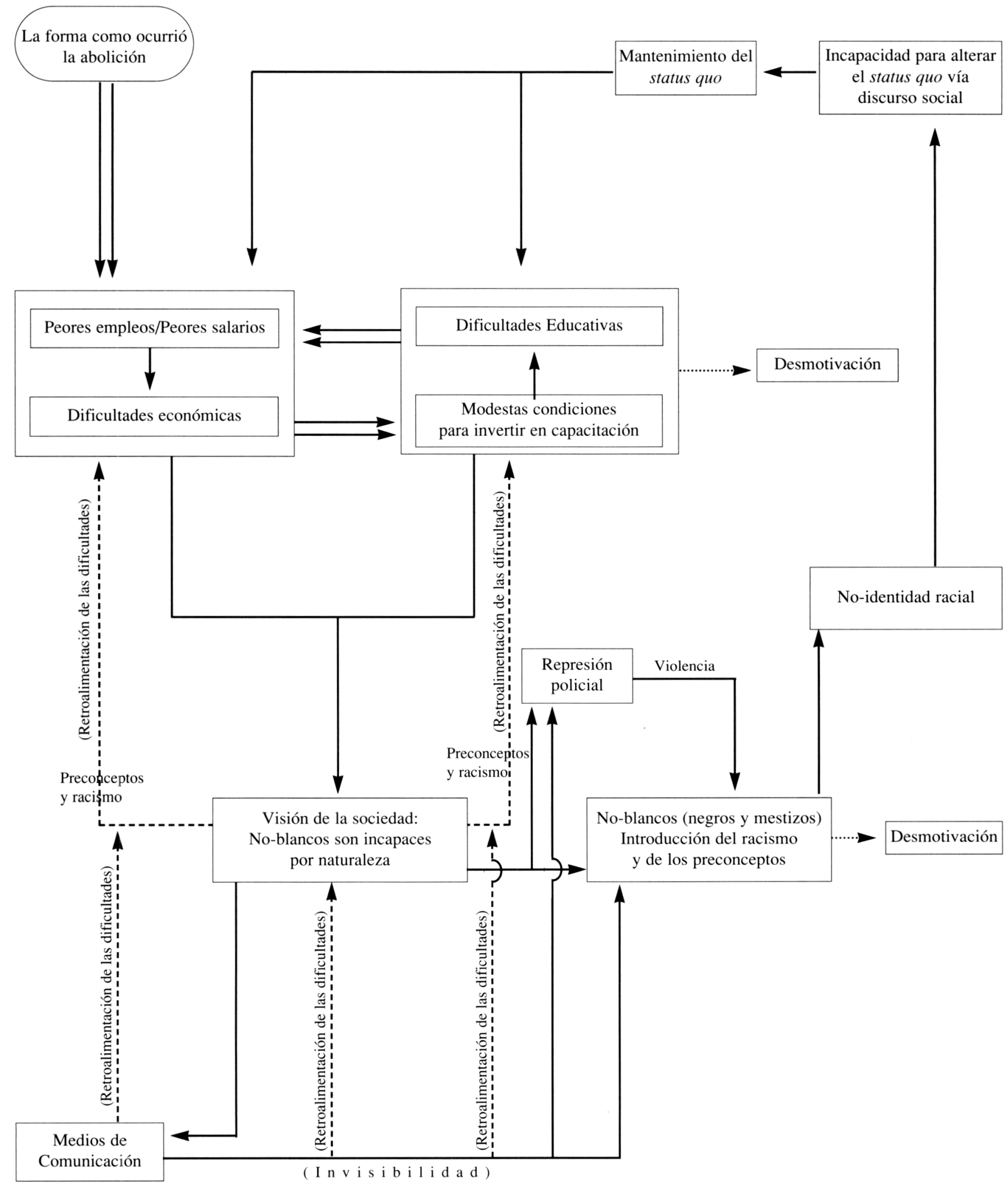


Tenemos, en ocasiones, un subsistema que retroalimenta a aquel que lo originó. Otras veces, tenemos un subsistema actuando de manera difusa que no sólo retroalimenta el foco generador, sino que también impulsa a diversos subsistemas. Este es el caso de los subsistemas "Visión de la Sociedad" y "Medios de Comunicación".

La "Visión de la Sociedad" tiene origen en el resultado que producen las dificultades económicas sumadas a las dificultades educativas. Tal dicotomía se convirtió en el estereotipo del negro brasileño, como una 'logomarca' que significa: pobre y sin capacitación. Ese es el punto de vista de la sociedad que retroalimenta las dificultades iniciales citadas. En la"Visión de la Sociedad", prejuiciosa y racista, se forma la idea a partir de la cual los "Medios de Comunicación" tratan a los negros, de la misma manera que fomenta la "Represión Policial" y acaba alcanzando a su víctima directamente, mediante la introyección de sus valores por parte de los no-blancos. Los "Medios de Comunicación”, a su vez, tienen una actuación parecida. Concretamente, son la voz de la sociedad y se confunden con ella en una actuación paralela, como una imagen y su sombra.

\section{LA APROXIMACIÓN SISTÉMICA EN LA TEORÍA DE CUESTIÓN NEGRA BRASILEÑA}

La técnica de razonar por el método cartesiano se basa en la división de un problema o asunto hasta llegar a un punto perfectamente inteligible respecto del tema en cuestión. De esta manera, el enfoque cartesiano se basa en lo que la lógica apunta: un dato global confunde e impide una interpretación correcta. Partiendo de esto, debe dividirse el problema en partes y subpartes hasta llegar a un perfecto entendimiento para el raciocinio. El camino contrario al apuntado por el método cartesiano fue el escogido por el Movimiento Negro Brasileño para enfrentar la problemática racial. Nos situábamos en lo general. Apuntábamos y denunciábamos las amarguras del pueblo negro. La actuación de la militancia negra no podría y no debería ser diferente. Sin embargo, Descartes no estudió muy bien las múltiples interrelaciones de las diversas partes contenidas en un problema. El proceso de feedback no consta en el método cartesiano.

La metodología sistémica tiene como esencia la comprensión de las múltiples interrelaciones de los diversos componentes de un problema. A partir de esa visión de conjunto, esa metodología posibilita conocer de manera integrada los diversos sectores existentes (Santos, 1988:48). Ahora, lo que le faltaba al método cartesiano fue aportado por la visión sistémica. Es lo que falta a aquellos que batallan por la cuestión racial en Brasil. Militantes y científicos actúan de forma que no perciben que la visión sistémica, con su carácter globalizante, facilita la comprensión del conjunto. Los militantes fueron y todavía son, en gran parte, generalistas. Los científicos "departamentalizan" la cuestión racial en "nichos" de su predilección: educación, violencia, cultura, comunicaciones, etc. Por otro lado, la población -negra y blanca- actúa en la cotidianeidad, y como esta instancia es dinámica e interdisciplinar, es necesario tener un "ojo sistémico" para descifrar el "ciempiés de dos cabezas" al que me referí al inicio. El esfuerzo hecho por militantes y científicos debe contemplar el funcionamiento de la vida en su día-a-día. Los militantes se encerraron en "guetos de discusión" y los científicos en "guetos departamentales".
Es importante explicitar bien el significado de la expresión "sistema". Para Churchman, a pesar de haber sido definida de muchas maneras, "todos los autores que están de acuerdo que un sistema es un conjunto de partes coordenadas para realizar un conjunto de finalidades" (Churchman, s/d:50). Para Maciel, "sistema es un conjunto de elemento ligados entre sí por cadenas de relaciones, de modo tal que constituyen un todo organizado" (Maciel, 1974:13). Estas definiciones manifiestan bien la interdisciplinariedad de la metodología sistémica y contemplan adecuadamente la problemática racial en Brasil tal y como la concebimos. Las intersecciones y conexiones, con sus entrelazamientos, son la esencia de la teoría circular esquematizada en el punto anterior y, al mismo tiempo, la característica que la enriquece.

Sin embargo, la utilización de la aproximación sistémica en problemas del día-a-día -de orden administrativo o de cuño más social- no obtuvo un éxito claro, en virtud de que la base inicial de la teoría de sistemas se dirigía hacia la biología. Había, pues, una cierta inadecuación

La jerarquización de sistemas es lo que viabiliza la metodología sistémica en problemas más amplios como la cuestión negra brasileña. El enfoque sistémico sin jerarquización no posibilita una perfecta comprensión del problema en virtud del elevado volumen de interrelaciones contenidas en el proceso. $\mathrm{La}$ jerarquización, como es utilizada en este estudio, auxilia a la metodología sistémica, dando a la teoría de la negritud un mayor sentido operacional. De esta manera, la jerarquización de sistemas es la aproximación sistémica utilizando modelos. Modelos para pensar y desarrollar un determinado tema (Bernardes, 1982). Para la cuestión de la negritud en Brasil, la jerarquización de sistemas es un camino adecuado para focalizar el conjunto sin perder de vista los múltiples aspectos implicados.

Lo que hicimos en este estudio fue la utilización esquemática de la idea planteada por el enfoque sistémico: la comprensión de las diversas interrelaciones de los múltiples componentes de un problema (como ocurre en la cuestión racial brasileña). Como la cuestión en estudio tiene una amplitud mayor, la jerarquización viene en socorro de la teoría de sistemas auxiliando y facilitando la creación de un modelo para pensar y desarrollar ese "ciempiés de dos cabezas" que constituye la cuestión de la negritud en Brasil.

\section{CONSIDERACIONES FINALES}

¿Cuál debe ser la aproximación correcta para interpretar el recorrido circular que traba el desarrollo pleno del negro en Brasil, en el sentido de trazar caminos que alteren ese cuadro en el futuro?

La sucesión de partes que explican y constituyen la vida del negro brasileño tiene una circularidad que vuelve difícil su interrupción. También porque las personas no identifican bien ese proceso circular. Como se ha visto, los estudiosos de esa cuestión se atuvieron, preferentemente, a aspectos aislados, sin hacer la necesaria conexión entre los diversos vectores del problema.

\section{El estudio interdisciplinario del recorrido del círculo vicioso.}

La manera adecuada de actuar en forma positiva en relación a la cuestión racial es seguir el propio recorrido del círculo vicioso. Sobre todo, es fundamental que jerarquicemos las 
diversas fases de la terapia a adoptar. Esto quiere decir: qué (y cómo) debe ser realizado, así como la intensidad de las diversas acciones a emprender.

En primer lugar, es importante recalcar que sólo es posible invertir la "Visión de la Sociedad" por la vía del proceso educativo. No existe un discurso o voluntad política de grupos o partidos que puedan hacerlo. En segundo lugar, no está fuera de lugar recordar que la población no-blanca forma parte de la sociedad. Esto quiere decir que negros y blancos deben pasar por una pedagogía específica a fin de invertir la marca estigmatizada de lo negro a lo largo de casi medio milenio. Con esto quiero decir que es en la educación donde se debe emprender el mayor esfuerzo para iniciar una nueva fase en la temática racial brasileña hace tanto tiempo empantanada. Esa nueva fase debe buscar dos cosas: - Generar conciencia en la sociedad de la inmensa contribución negra en la formación de lo que somos como nación. Esto, a medio plazo, debe llevar a los blancos a reivindicar su parte negra. Para ello, tal terapia pedagógica debe poner en evidencia, en forma competente, que somos más ricos, culturalmente, que la blanca Europa (en cierta forma medio decadente) por tener como base una matriz mixta, consustanciada en diversas culturas entre las que la africana se destaca de manera especial. No se trata sólo de la musicalidad -reconocida por todos-, de nuestro fuerte paladar o aún de nuestras habilidades múltiples, también confirmadas por extranjeros que nos estudian. Se trata, sobre todo, de nuestra forma de contemplar el mundo y la propia vida. En fin, al reivindicar su lado negro, la "Visión de la Sociedad" será, precisamente, lo contrario de lo que ocurrre hoy.

Para la población negra y mestiza, esa terapia pedagógica reversiva afirmará su identidad racial. Ese escenario nos remite a algo fantástico, comparado con lo que tenemos hoy: diversos tipos de no-blancos, mestizos de piel clara, "negros de poca tinta", como se dice en San Pablo, reivindicando su lado negro con firmeza y orgullo, sabiendo que ése es un punto positivo de su personalidad.

Hablamos antes de que no creemos en un cambio significativo sin que el área académica lo apoye. El proceso educativo depende inicialmente de la voluntad política. Sin embargo, esa voluntad sola no produce el material de la pedagogía recuperadora requerida para la tarea de transformación. Corresponde a los investigadores y estudiosos de la psicología (especialmente la social), pedagogía, historia, economía, antropología, demografía, geografía humana y sociología un esfuerzo significativo para que se avance en la temática racial brasileña. Es importante también la implementación de investigaciones en dos áreas cruciales que han actuado mucho más de lo necesario: la comunicación social y el derecho. Por otro lado, la economía y la geografía son áreas que históricamente no han contribuido a la temática racial brasileña. Es importante enfatizar que la manera adecuada de actuación es interdisciplinar, a fin de que sistemáticamente se trabaje el conjunto, que es complejo y dinámico.

Tanto el machismo como el racismo son comportamiento arraigados, cuyos orígenes son antiguos en el planeta. No obstante, los dos tienen sus peculiaridades. Con eso queremos decir que el machismo y el racismo brasileños son harina de la misma molienda; pero no del mismo saco, pues están alojados en "compartimentos" distintos de la sociedad. No cabe aquí traer las innumerables similitudes existentes entre ambos. Sin embargo, la pedagogía a adoptar tiene, sin duda, semejanzas.

El Seminario llevado a cabo en la Universidad de Sao Paulo, al sugerir la instalación de un centro o núcleo interdisciplinar, llegó a la conclusión de que debe existir un sector que coordine los trabajos a fin de tratar el conjunto de ellos sistémicamente. La producción científica de un centro de estudios con tal característica sistematizadora tomaría en cuenta los diversos aspectos de la temática racial cambiando, en nuestra opinión, lo que ha sido hasta hoy y que, finalmente, es la esencia de lo que sugiere la Teoría del Círculo Vicioso. En ese sentido, se presentó al rectorado de la Universidad de Sao Paulo, un documento proponiendo la creación del Núcleo de Estudios Interdisciplinarios sobre la temática de la cuestión negra en Brasil. La propuesta, hecha por un grupo de docentes e investigadores, busca no sólo rescatar la tradición de la Universidad de Sao Paulo en el área, sino también hacer avanzar el conocimiento y el interés por la temática -trabajo a ser desarrollado por la vía interdisciplinaria.

De acuerdo con lo expuesto, finalizamos señalando para el Movimiento Negro Brasileño tres caminos que deben orientar la actuación en cuanto movimiento social en un país con las características de Brasil:

- Buscar en la academia un aliado vigoroso, clarificador y creativo, que nos auxilie en la gestación de la pedagogía recuperadora a la que hemos hecho referencia. Al mismo tiempo, luchar para que el Estado se responsabilice de la ejecución material de la idea, ya que constitucionalmente están consignados los derechos de los negros.

- Batallar por la conquista de medios que viabilicen la comunicación. En un país de dimensiones continentales como Brasil, con más de 4 mil municipios, no es posible enfatizar nuestra tradición oral. Aquí la oralidad tiene la eficacia del tam-tam (instrumento utilizado por las comunidades africanas para comunicarse entre sí...) O sea, ninguna. Sin los medios de comunicación de masa: radio y especialmente la TV, no tenemos como vincular ideas y hechos. Estamos desenganchados, no hay estrategia posible sin eso.

- Nuestro éxito (o nuestro fracaso) pasa por un desafío sobre el cual siempre advertimos: el riesgo de partidización de la cuestión racial. Ninguno de los partidos existentes -precisamente ninguno- dan a lo negro su justa dimensión. La razón de esta afirmación es simple: los liderazgos partidarios blancos forman parte de la sociedad brasileña y tienen sus respectivas visiones de centro, izquierda, derecha, centro-izquierda y centro-derecha (con sus posibles variaciones) -considerando lo que eso representa hoy- sin tener en cuenta que la democracia en Brasil pasa por la cuestión racial. Además, no siempre el discurso racial (cuando existe) y la práctica de esos liderazgos han sido consistentes.

El trinomio expuesto exige del Movimiento Negro, o lo que pueda existir más consolidado de él, una actuación cuyo vector tenga un cuño estratégico, en vez de mantener una postura operativa, en nada coincidente con el movimiento que vive el país y, particularmente, con la invisibilidad a que estamos relegados todos.

\section{REFERENCIA BIBLIOGRÁFICAS}

Bernardes, C. (1982): Sistemas Hierarquizados na Administraçao e Culturas Organizacionais. Tese de Livre-Docência. Sao Paulo. FEA/USP.

Churchman, C.W. (1971): Introduçao à Teroria dos Sistemas. Petrópolis. Ed.Vozes. 
CuRY, C.R.J. (1985): Educaçao e Contradiçao: elementos metodológicos para uma teoría crítica do fenômeno educativo. Sao Paulo. Ed.Cortez.

Golden, H. (1964): Kennedy e os Negros. Sao Paulo. Livraria Matins Editora.

GoNÇALVES, L.A.O. (1987): "Reflexao sobre a particularidade cultural na educaçao das cianças negras". (Raça negra e educaçao). Cadernos de Pesquisa.Sao Paulo, Fundaçao Carlos Chagas, 63 (3), set/out/nov/dez. 1987

Maciel, J. (1974): Elementos de Teoria Geral de Sistemas. Petrópolis, Ed.Vozes.

Munanga, K. (1990): "Racismo: da desigualdade à intolerância". Sao Paulo em Perspectiva. Sao Paulo, Fundaçao Seade, 4(2), abr/jun.1990.
_ (1991): Negritude Afro-Brasileira: perspectivas e dificultades. Sao Paulo, mimeo.

OLiveiRA, L.E.G. de et alii. (1981): O Lugar do Negro na Força de Trabalho. Rio de Janeiro, Fundaçao IBGE.

Penteado, J.R.W. (1993): "Brasileiros invisíveis". O Estado de S.Paulo. Sao Paulo, 12/01/93.

RoSEMBERG, F. (1987): "Relaçoes raciais e rendimento escolar". (Raça negra e educaçao). Cadernos de Pesquisa. Sao Paulo, Fundaçao Carlos Chagas, 63(3), set/out/nov/dez.1987.

Santos, H. de S. (1988): O uso de Sistemas Hierarquizados em Análise dos Demonstrativos Financeiros. Tese de Doutorado. Sao Paulo, FEA/USP.

Silva, N. do V. (1980): "O preço da cor: diferenciais raciais na distribuçao de renda no Brasil". Pesquisa e Planejamento Econômico. Rio de Janeiro, 10(1), abril 1980.

\section{RESUMEN}

El artículo trata de resaltar la necesidad de encontrar una teoría específica para el estudio pero también para la mejora social de la población negra (no blanca) en el Brasil actual. Santos destaca la importancia de la teoría sistémica para entender el recorrido del círculo vicioso en el que se encuentra esta población. Este círculo se completa con unos ingresos inferiores y una escolaridad inferior, violencia cotidiana y policial, y así el círculo se repite una vez tras otra.

\section{ABSTRACT}

The article tries to underline the necessity to find a specific theory to explain but also to improve socially the black (non-white) sectors of brazilean society. Santos stands out the importance of the sistemic theory in order to undestand the way of the viciuous circle in which there is this population. This circle is completed with low incomes and low education, daily and policial violence and so the circle begins again and again. 